\title{
Variability in group size and daily activity budget of family groups of the gelada baboon (Theropithecus gelada) at Guassa Community Conservation Area, Central Ethiopia
}

Mandefero Mamo and Tilaye Wube

\begin{abstract}
Background: The gelada baboon, Theropithecus gelada Ruppell, 1835, is an endemic primate of the central and western highlands of Ethiopia occurring between altitudes of 1800-4400 m. Variability in activity time budget between the two gelada social units, i.e., one-male units (OMUs) and all-male units (AMUs), has not been studied previously. Thus, the present study was an effort to understand intra- and inter-variations in group size and daily activity time budget in gelada baboon OMUs and AMUs at Guassa Community Conservation Area, Central Ethiopia. The instantaneous sampling method was used in the data collection.

Results: Both OMU and AMU groups allocated more time for feeding (OMUs = 36.96\%; AMUs = 35\%) followed by moving (OMU = 25.8\%; AMUs = 27\%). Grooming was the most frequent social activity in both family groups (OMUs $=8.56 \%$; AMUs = 11.81\%). OMUs and AMUs did not show significant variation between themselves in the time budget and temporal distribution of their daily activities. However, the overall variation in the time budget allocated for daily activities within OMUs and AMUs was statistically significant $(p<0.05 \%)$. The different age and sex groups in OMUs (i.e., immature, sub-adult females, subordinate males, adult females, and alpha males) showed statistically significant variation in their time budget allocation for the daily activities $(p<0.05)$ except for feeding and moving. Alpha males had the highest proportion of resting (32.14\%) and aggression (31.92\%). Immature individuals were responsible for $>90 \%$ of the time budget recorded for playing while adult females showed the highest frequency of grooming. Group size of OMUs ranged between 5 and 15 individuals (mean \pm SD $=11.25 \pm$ 1.95). Adult females comprised the highest number within OMUs (mean $=4.5$ ) followed by immature individuals $($ mean $=3)$. The group size of AMUs ranged from 4 to 8 (mean $\pm S D=6.6 \pm 1.5)$.
\end{abstract}

Conclusion: Our results showed that the gelada baboon spent less time on foraging compared to previous studies at the Simien Mountains and Debre-Libanos area. We suggested this variation could be explained based on higher forage quality at Guassa Community Conservation Area resulting from better conservation of the habitat.

Keywords: Afro-alpine, AMU, Central Ethiopia, Gelada baboons, OMU, Social behavior, Social units

\footnotetext{
* Correspondence: tilaye.wube@aau.edu.et

Department of Zoological Sciences, College of Natural and Computational

Sciences, Addis Ababa University, P.O. Box 1176, Addis Ababa, Ethiopia
}

(c) The Author(s). 2019 Open Access This article is distributed under the terms of the Creative Commons Attribution 4.0 International License (http://creativecommons.org/licenses/by/4.0/), which permits unrestricted use, distribution, and reproduction in any medium, provided you give appropriate credit to the original author(s) and the source, provide a link to the Creative Commons license, and indicate if changes were made. The Creative Commons Public Domain Dedication waiver (http://creativecommons.org/publicdomain/zero/1.0/) applies to the data made available in this article, unless otherwise stated. 


\section{Background}

The gelada baboon, Theropithecus gelada Ruppell, 1835, is an endemic primate of the central and western highlands of Ethiopia occurring between altitudes of 1800$4400 \mathrm{~m}$ (Walker 1975; Gippoliti and Hunter, 2008). It is associated with gorges, precipices, and moorland habitats. Geladas spend the night on steep cliffs that provide safe sleeping sites (Walker 1975; Gippoliti and Hunter 2008). Grass leaves are the preferred diet while subterranean stems and rhizomes are consumed during the dry season. Geladas can also raid crops when there is agricultural encroachment into their habitats (Walker 1975; Iwamoto and Dunbar 1983; Gippoliti and Hunter 2008).

Geladas live in multilevel social groups. The basic social groups are the reproductive one-male units (OMUs) and the bachelor all-male units (AMUs). One-male units can have 1 to 12 adult females with their young and 1 to 4 males including the breeding alpha male, while the AMUs can be composed of 2-15 males (Gippoliti and Hunter 2008; Snyder-Mackler et al. 2012). The next higher social level is the band that contains 30 to 260 animals organized in 2 to 30 OMUs and several AMUs. Different bands form herds that last a short period of time (Gippoliti and Hunter 2008; Roux et al. 2011; Snyder-Mackler et al. 2012).

Gelada reproductive units have a dominant female that plays a role in maintaining coordination between the alpha male and its other females (Dunbar and Dunbar 1977; Dunbar 1983). Dunbar and Dunbar (1977) and Dunbar (1980) suggested the dominant female has enhanced reproductive success. Dunbar (1980) also suggested the dominant female harasses the subordinate females causing stress that eventually leads to reproductive suppression through anovulatory cycles and amenorrhea. However, Roux et al. (2011) reported the lack of evidence to support this. The spatial integrity of gelada reproductive units is maintained by the alpha male and the dominant female that chase away members of other units and give support to members of their own (Dunbar and Dunbar 1977; Dunbar 1983). Social bonds in gelada reproductive units are strengthened by social behavior such as playing (Mancini and Pelagi 2009) and probably grooming as suggested for most primates (Lehmann et al. 2007). Mancini and Pelagi (2009) observed adult female geladas playing with other adult females as much as they play with the immature. Female geladas stay in their natal units throughout life while the males leave their unit to join AMUs (Gron 2008; Roux et al. 2011). Males stay in the AMUs for $2-4$ years before they attempt to get breeding opportunities through a takeover of a reproductive unit or by joining as subordinates and later breaking away from the unit with some of the females (Gron 2008).

The daily activity time budget of gelada baboon was studied recently both in the wild (Woldegeorgis and
Bekele 2015; Abie et al. 2017) and in a zoo (Filipcik et al. 2014). However, these studies did not examine variability in activity time budget between the two gelada social units, i.e., OMUs and AMUs. The variations in demographic composition and specific social role of members of OMUs and AMUs might affect the dynamics of their social interactions and hence their activity budget. Therefore, the present study was an attempt to examine the following: (1) variability in daily activity time budget within and between OMUs and AMUs, (2) interactions between OMUs and AMUs, (3) the specific time budget allocated for grooming and direction of grooming, and (4) the mean group size of OMUs and AMUs.

\section{Methods}

\section{Study area}

The study was conducted in the Guassa Community Conservation Area (GCCA) also known as Guassa Park, located in the central highlands of Ethiopia, North Shoa Zone of Amhara National Regional State (Fig. 1). GCCA is $265 \mathrm{~km}$ northeast of the capital Addis Ababa. The area is located between $10^{\circ} 15^{\prime}-10^{\circ} 27^{\prime} \mathrm{N}, 39^{\circ} 45^{\prime}-39^{\circ} 49^{\prime} \mathrm{E}$ with an altitudinal range of 3200-3700 m (Tefera 2001). The vegetation of GCCA is characterized by a high altitude afro-alpine vegetation with different vegetation communities including Festuca grassland, Euryops-Festuca grassland, Euryops-Alchemilla shrubland, Helichrysum-Festuca grassland, Erica moorland, and swamp grassland (Tefera 2001). The fauna at GCCA harbors unique assemblage of wild animals including 14 species of endemic birds including the restricted-range Ankober seedeater Carduelis ankoberensis synonym Crithagra ankoberensis Ash, 1979 and spot-breasted plover Vanellus melanocephalus Ruppell, 1845 (Tefera and LeaderWilliam 2005). The area is also one of the distribution ranges of the Ethiopian wolf Canis simensis Ruppell, 1840 (Yalden et al., 1977; Tefera and Leader-William 2005). The natural habitat and resources at GCCA have been well preserved through a traditional system of community conservation practice for hundreds of years (Tefera 2005).

The climate of GCCA varies with altitudinal gradient and seasonal changes. At higher altitudes, the wet season is characterized by a combination of high rainfall, hailstorms, and occasional snow. During the dry season, frosts are common. Even though showers of light rain can occur in any month of the year, the distribution of rainfall in the Guassa area is characterized by a bimodal pattern. A short rainy season occurs during FebruaryApril, and the main rainy season mostly occurs between June and September. The annual rainfall ranges from 1200 to $1600 \mathrm{~mm}$ (Tefera 2001). There is sharp temperature fluctuation between night and daytime due to the altitudinal differences and the size of the 


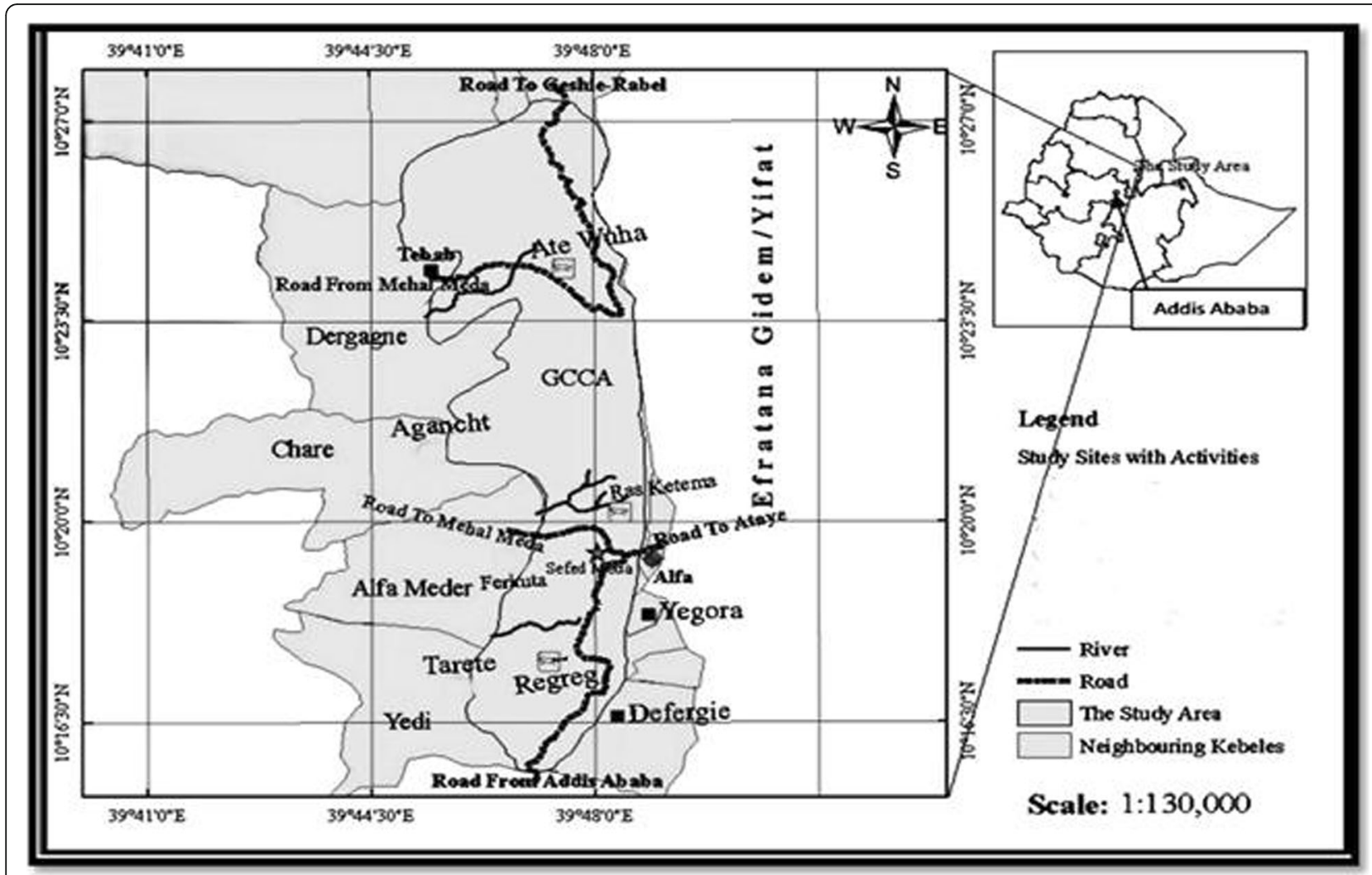

Fig. 1 Map of GCCA with adjacent Kebeles (smallest administration units) (source: Andarge 2010)

mountain block. The temperature is characterized by mild days and cold nights. In the driest months (December-February), daytime temperature can rise to $25{ }^{\circ} \mathrm{C}$, while nighttime temperature could fall to $-7^{\circ} \mathrm{C}$ (Tefera 2001).

\section{Data collection}

Instantaneous scan sampling method was used to collect the data (Altmann 1974). Data were collected from randomly selected OMU and AMU focus groups within the gelada populations at the study area (GCCA). Behavioral data recording was conducted for a total of 12 days each for OMUs and AMUs between August and November 2017. Data collection days for OMUs and AMUs were distributed consecutively. The geladas were habituated to the presence of the researcher (MM) before data collection started. In each day of data collection, a randomly selected focus group of OMU or AMU was followed throughout the day at a distance of $\leq 10 \mathrm{~m}$. The daily data collection (scanning) period was divided into three: morning (07:00-11:00 h), midday (12:00-14:00 h), and afternoon (15:00-18:00 h). Activities displayed (feeding, moving, resting, playing, aggression, mating, and grooming) by each social unit member were recorded for the first $10 \mathrm{~min}$ followed by a 10-min pause. Recording was then resumed for another $10 \mathrm{~min}$. Thus, we used three separate scanning periods of $10 \mathrm{~min}$ in each hour. Members of OMUs were classified as immature (including infants, yearlings, and juveniles), sub-adult females, subordinate males, adult females, and alpha males according to Kawai et al. (1983).

\section{Data analysis}

The nonparametric $x^{2}$ test was used to compare variations in percentage frequencies of activities and group size within OMUs and AMUs. The group size variation between OMUs and AMUs was compared using independent samples $t$ test. The 95\% confidence interval was used to determine level of significance. The data analysis was done using SPSS statistical software ver. 17.

\section{Results}

Activity time budget of OMUs and AMUs

Both OMU and AMU gelada units allocated most of their time for feeding: $36.96 \%$ and 35\% respectively. Moving and resting were the next most frequent activities: $25.8 \%$ and $15 \%$ (OMUs) and $27 \%$ and $16.5 \%$ (AMUs) respectively. Grooming was the most frequent social activity in both units: $8.56 \%$ (OMUs) and $11.81 \%$ (AMUs). Aggression was displayed more frequently in AMUs (5.89\%) than OMUs (1.69\%) while playing was more common in OMUs. There was a significant 


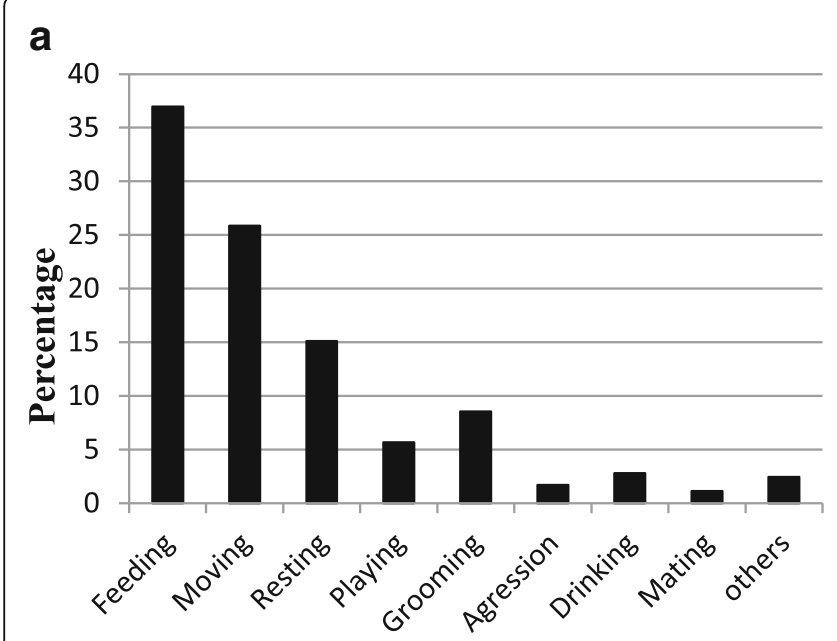

Activities

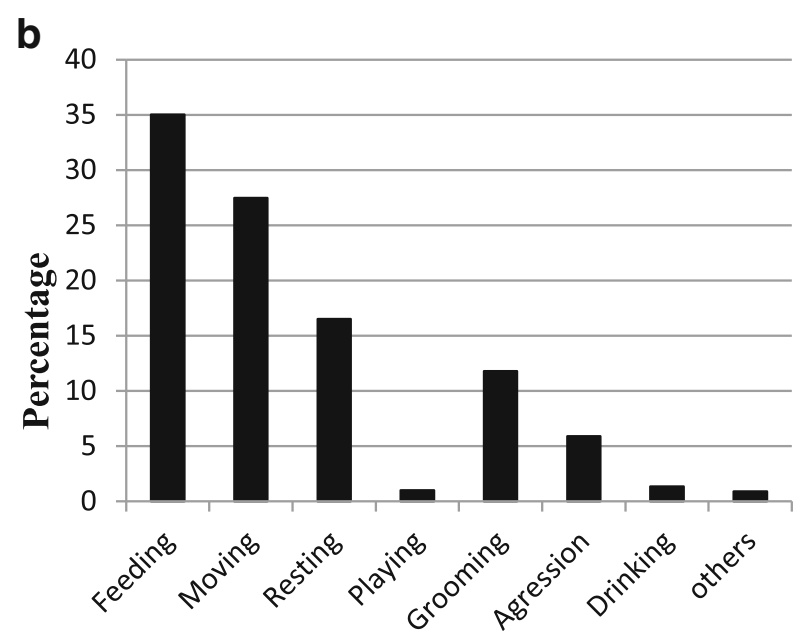

Activities

Fig. 2 Total percentage of daily activities in OMUs (a) $(n=135)$ and AMUs $(\mathbf{b})(n=80)$

difference in the proportion of time allocated for the different daily activities in both OMUs and AMUs $(p<$ 0.05). Pair-wise comparison of the percentage proportion of time allocated for each of the daily activities between OMUs and AMUs did not show statistically significant variation $(p>0.05)$ (Fig. 2a, b).

\section{Variations within OMUs}

Sub-adult females (26.37\%) and adult females (21.28\%) had the highest percentages of the total feeding records within OMUs. The alpha males had the highest proportion of resting time (32.14\%) and display of aggression $(51.06 \%)$ while subordinate males were the next group that showed more aggression behavior (31.92\%). More than $90 \%$ of playing was recorded in immature individuals while adult females had the highest frequency of playing compared to the remaining age and sex classes (3.8\%). Alpha males were never observed playing during the study. Grooming was most frequently observed in adult females (32\%) followed by sub-adult females and the alpha males (22\% each) (Table 1). Except feeding and moving, the time budget allocated by the different agesex categories was significantly different $(p<0.05)$ between each other.

\section{Temporal variation in activity budget}

In the OMUs, most of the grooming (61.34\%) and playing (54.43\%) was observed during the morning (7:00-11: $00 \mathrm{~h})$. Resting $(61.39 \%)$ and mating $(71.88 \%)$ were also predominantly observed in the morning while most feeding (64.5\%), moving (45.2\%), and drinking (48.72\%) took place in the afternoon (15:00-18:00 h). Similar pattern of temporal activity time budget allocation was observed in AMUs where most of the resting (65.85\%), playing $(42.5 \%)$, and grooming $(60.65 \%)$ were recorded in the morning. Similarly, most of the feeding (61.32\%), moving (44.23\%), and drinking (52.83\%) were recorded during the afternoon (Fig. 3a, b).

\section{Direction of grooming in OMUs}

Adult females directed the highest proportion of their grooming (38.16\%) towards the alpha male followed by grooming of immature individuals (28.94\%) while subordinate males rarely received grooming from the adult females (1.32\%). Adult females also received the highest grooming within the OMUs. However, they did not receive grooming from subordinates at all. Instead, the subordinates directed most of their grooming towards each other (58.33\%) and sub-adult females (30.56) (Table 2).

Table 1 Total percentage of time allocated for daily activities by members of the different age-sex categories of OMUs

\begin{tabular}{|c|c|c|c|c|c|c|c|c|c|}
\hline Age and sex category & Feeding & Moving & Resting & Grooming & Playing & Aggression & Drinking & Mating & Others \\
\hline Immature $(n=37)$ & 16.96 & 22.53 & 11.19 & 9.24 & 93.67 & 0.0 & 17.94 & 0.0 & 22.06 \\
\hline Sub-adult females $(n=17)$ & 26.37 & 19.33 & 16.43 & 21.85 & 0.63 & 4.26 & 16.67 & 0.0 & 4.41 \\
\hline Adult females $(n=54)$ & 21.28 & 18.64 & 22.38 & 31.93 & 3.8 & 12.76 & 41.03 & 50.0 & 26.47 \\
\hline Subordinate males $(n=15)$ & 18.04 & 21.28 & 17.86 & 15.13 & 1.9 & 31.92 & 16.67 & 0.0 & 20.59 \\
\hline Alpha males $(n=12)$ & 17.35 & 18.22 & 32.14 & 21.85 & 0.0 & 51.06 & 7.69 & 50.0 & 26.47 \\
\hline
\end{tabular}




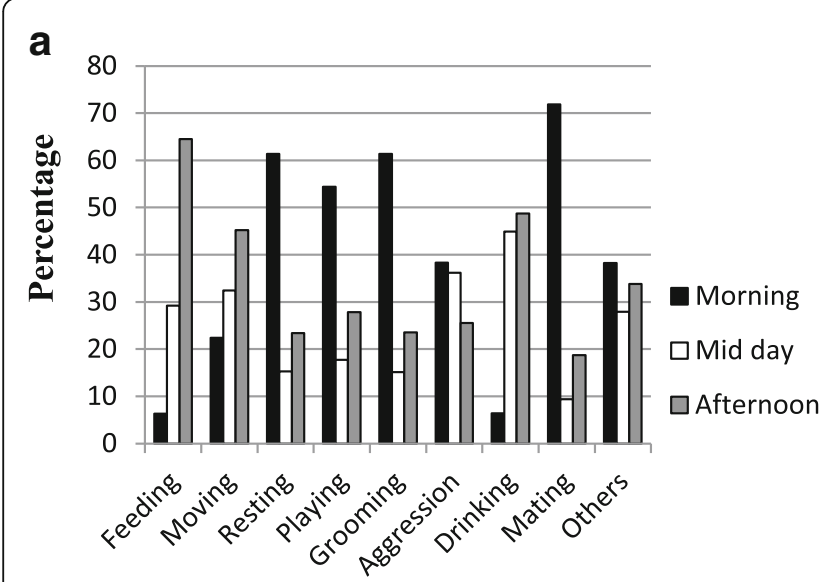

Activities

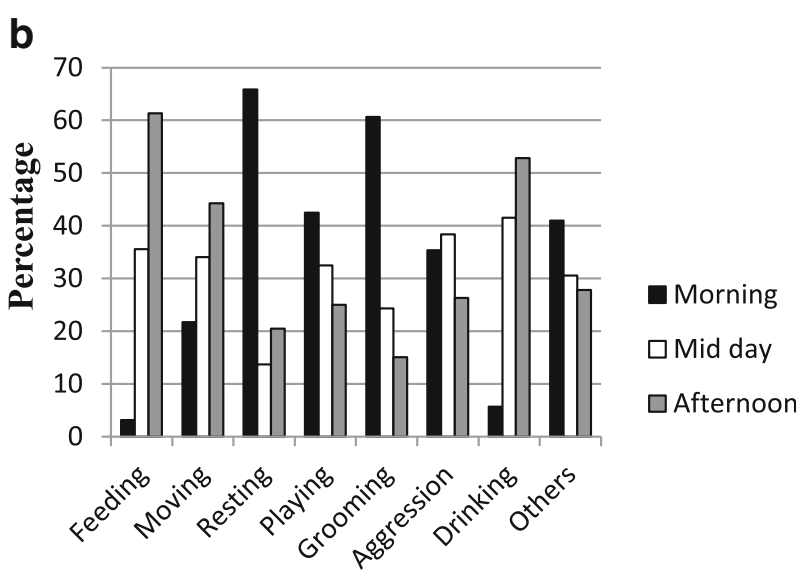

Activities

Fig. 3 Temporal variation in total percentage activity time budget of OMUs $(\mathbf{a})(n=135)$ and AMUs (b) $(n=80)$

\section{OMU-AMU interactions}

The alpha males of different OMUs showed tolerance towards each other. They even cooperated to drive away bachelor males of AMUs that come too close to their harem. Cooperation was also observed between other members of neighboring OMUs to protect their respective units from the bachelor males that might attempt a takeover. The bachelor males in the AMUs were frequently aggressive and hyperactive around the OMUs as they attempt to get a chance of mating with the females in the OMUs.

\section{Group size}

Group size of OMUs ranged between 8 and 15 individuals (mean $\pm \mathrm{SD}=11.25 \pm 1.95)$, and the variation was not statistically significant $(p=0.062)$. Group size of 12 individuals was the most frequent $(n=7,58 \%)$ out of the 12 OMUs studied while there was only one OMU with a group size of 15 individuals (Table 3 ). The mean number of adult females was the highest in the OMUs (4.5 individuals) followed by immature (3.08 individuals) (Table 3).

The group size of AMUs ranged between 4 and 8 individuals (mean $\pm \mathrm{SD}=6.6 \pm 1.5$ ). Group size of 8 was the most frequent $(n=6 ; 50 \%)$ among AMUs followed by 6 $(n=4 ; 33 \%)$ (Table 4$)$. The variation in group size of
AMUs was also not statistically significant $(p=0.368)$, but the difference in group size of OMUs and AMUs was statistically significant $(p=0.00)$.

\section{Discussion}

Our results revealed both OMU and AMU gelada groups have symmetrical pattern of time budget and temporal distribution of their activities at the present study site. This might suggest that even though gelada family units are distinct, there is synchronization of social roles due to the social proximity of OMUs and AMUs. This could be more the case in gelada family units that belong to the same band.

Compared to previous studies at Gich Plateau (Woldegeorgis and Bekele 2015) and Debre-Libanos area (Abie et al. 2017), the gelada at GCCA spent less time on foraging and invested more on moving and resting. Iwamoto and Dunbar (1983) reported feeding activity increased with altitude due to temperature-dependent energy requirements and declining habitat quality. Even though Gich Plateau in the Simien Mountains is located at a higher altitude (around $4000 \mathrm{~m}$ ), the other study site (Debre-Libanos) is lower (2150-2650 m) compared to GCCA (3200-3700 m). Therefore, altitudinal variation may not fully explain the observed difference in foraging time. Probably, the density of preferred food, i.e., grass

Table 2 Total percentage distribution of grooming between members of OMUs

\begin{tabular}{|c|c|c|c|c|c|}
\hline \multirow[t]{2}{*}{ Grooming } & \multicolumn{5}{|l|}{ Groomed } \\
\hline & Immature & Sub-adult females & Adult females & Subordinate males & Alpha males \\
\hline Immature $(n=37)$ & 9.09 & 18.18 & 59.09 & 4.55 & 9.09 \\
\hline Sub-adult females $(n=17)$ & 9.62 & 26.92 & 55.77 & 5.77 & 1.92 \\
\hline Adult females $(n=54)$ & 28.94 & 9.21 & 22.37 & 1.32 & 38.16 \\
\hline Subordinate males $(n=15)$ & 11.11 & 30.56 & 0.0 & 58.33 & 0.0 \\
\hline Alpha males $(n=12)$ & 1.92 & 9.62 & 88.46 & 0.0 & 0.0 \\
\hline
\end{tabular}


Table 3 Group size and age-sex composition of OMUs $(n=12)$

\begin{tabular}{|c|c|c|c|c|c|c|}
\hline \multirow[t]{2}{*}{ Group no. } & \multicolumn{5}{|c|}{ Number of studied animals in the different age-sex categories of OMUs } & \multirow[t]{2}{*}{ Total } \\
\hline & Immature & Sub-adult females & Adult females & Subordinate males & Alpha males & \\
\hline 1 & 2 & 2 & 3 & 0 & 1 & 8 \\
\hline 2 & 2 & 1 & 3 & 1 & 1 & 8 \\
\hline 3 & 3 & 1 & 4 & 1 & 1 & 10 \\
\hline 4 & 3 & 2 & 4 & 2 & 1 & 12 \\
\hline 5 & 2 & 2 & 6 & 1 & 1 & 12 \\
\hline 6 & 3 & 2 & 4 & 2 & 1 & 12 \\
\hline 7 & 4 & 2 & 4 & 1 & 1 & 12 \\
\hline 8 & 4 & 2 & 6 & 2 & 1 & 15 \\
\hline 9 & 5 & 1 & 4 & 1 & 1 & 12 \\
\hline 10 & 2 & 1 & 6 & 2 & 1 & 12 \\
\hline 11 & 3 & 1 & 4 & 1 & 1 & 10 \\
\hline 12 & 4 & 0 & 6 & 1 & 1 & 12 \\
\hline Total (individuals) & 37 & 17 & 54 & 15 & 12 & 135 \\
\hline Mean \pm SD (individuals) & 3.08 & 1.42 & 4.5 & 1.25 & 1 & $11.25 \pm 1.95$ \\
\hline
\end{tabular}

leaves, in GCCA is higher than the other two study areas due to altitude-independent factors such as soil fertility and better state of conservation. Guassa Community Conservation Area has been strictly conserved by the community through a traditional system for hundreds of years (Tefera 2005). This is also supported by Woldegeorgis and Bekele (2015) who mentioned resource limitations at Gich Plateau. The gelada at GCCA have also displayed more aggression and playing than the other studied populations. Table 5 compares the results of the present study with the previous ones.

The daily pattern of foraging time budget was similar to the populations from the Simien Mountains where foraging was maximum during midday and in the afternoons. Resting also showed similarity between populations of GCCA and Simien Mountains where the highest time budget of resting was allocated in the morning. This was consistent with previous knowledge of gelada behavior that they sunbath for several hours before becoming active during the day (Walker 1975). However, there was a difference between the two populations in the temporal allocation of time for moving. In the present study, moving was the highest during the morning, while in the Simien Mountains, there was no marked temporal variation throughout the day (Woldegeorgis and Bekele 2015).

The absence of significant variation in feeding time among the different age and sex groups of the OMUs is interesting in light with previous knowledge. Dunbar and Dunbar (1988) reported that lactating females increased feeding time with age of infant and the rate of increase is affected by nutritional quality and the extent of foraging by the infant. This goes in line with our assumption on the prevalence of high nutritional quality and quantity at the gelada habitat in GCCA. On the other hand, adult females had the highest frequency of drinking. This might be due to lactating females that have additional water demand (Bronson, 1998). The significant variation in allocated activity budget except feeding and moving by the different sex-age categories of OMUs reveals variability in social role play. For instance, the alpha males spend more time resting compared to others while adult females and immature do most of the grooming and playing respectively.

Our study revealed grooming-related bonds between adult females and immature, adult females and alpha males, sub-adult females and adult females, among subordinate males, and subordinate males and sub-adult females. The social bond between adult females and immature could be explained by maternal-offspring association and that of the adult female with the alpha male by sexual attraction and mating solicitation. Adult females, particularly the dominant female, play a major role in stabilizing order in the OMUs (Dunbar 1983;

Table 4 Group size of AMUs $(n=12)$

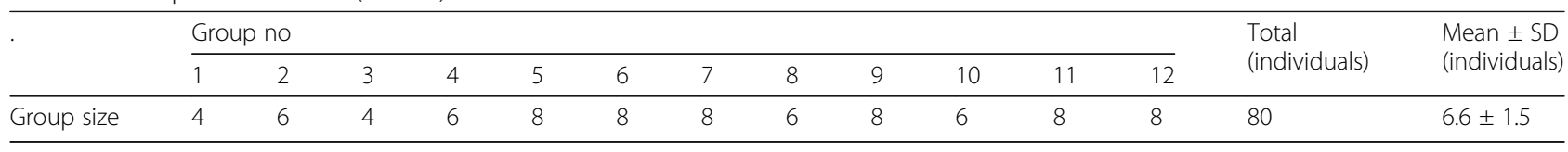


Table 5 Comparison of the percentage of time allocated to different activities by gelada baboon between the present and previous studies

\begin{tabular}{lllll}
\hline Activities & $\begin{array}{l}\text { Debre-Libanos (Central } \\
\text { Ethiopia) (Abie et al. 2017) }\end{array}$ & $\begin{array}{l}\text { Simien Mountains (Northwest Ethiopia) } \\
\text { (Woldegeorgis and Bekele 2015) }\end{array}$ & $\begin{array}{l}\text { Zlin-Lesna Zoo (Czech } \\
\text { Republic) (Filipcik et al. 2014) }\end{array}$ & $\begin{array}{l}\text { GCCA (Central Ethiopia) } \\
\text { (present study) }\end{array}$ \\
\hline Feeding & 56.12 & 56.6 & 44.1 & 35.9 \\
Moving & 16.76 & 14.1 & 8.1 & 26.6 \\
Resting & 9.42 & 10.7 & 7.7 & 15.8 \\
Playing & N/A & 1.7 & 1.7 & 3.35 \\
Grooming & N/A & 17.3 & N/A & 10.2 \\
Aggression & N/A & 0.9 & 0.7 & 3.79 \\
Drinking & N/A & N/A & N/A & 2.08 \\
\hline
\end{tabular}

N/A not available

Roux et al. 2011). As a result, they might be considered as the authority figures by the sub-adult females. Therefore, it could be suggested that the sub-adult females dedicate most of their grooming towards the adult females as a sign of subordination and an attempt to increase their chance of long-term acceptance in the group. It was previously reported that female geladas have enhanced sensitivity and emotional tuning towards companions (Palagi et al. 2009). Mancini and Palagi (2009) reported gelada females play with adult females as much as they play with the immature suggesting the use of such interactions to strengthen social bonds. Adult females displayed the highest frequency of grooming in the OMUs (32\%) which might provide evidence for their role in group stabilization and cohesion (Dunbar 1983). Dunbar (1991) suggested that grooming is not restricted to hygienic function but rather has a social function as well. Enhanced activity of adult females in grooming, sexual, and agonistic activities was also reported previously (Vaughan et al. 2000). Subordinate males apparently have little or no access to socialize with adult females. Therefore, they tended to turn to each other and the sub-adult females. This association might help them to recruit support and allegiance to enhance their success during a break-off attempt with some of the females and establish an OMU of their own (Gron 2008).

\section{Conclusion}

In conclusion, we report (1) the absence of variation in the frequency and temporal distribution of daily activities between OMU and AMU gelada groups at GCCA; (2) gelada populations at GCCA show peak foraging and movement during the afternoon while resting and socializing (playing and grooming) predominantly took place during the morning; (3) adult females were involved in most of the grooming activities (both receiving and giving) strengthening previous claims about their role in group cohesion and stability; and (4) gelada at GCCA had lower foraging time compared to those from Gich Plateau at Simien Mountains and Debre-Libanos area which might be due to higher quality and quantity of forage at GCCA.

\section{Abbreviations}

AMUs: All-male units; GCCA: Guassa Community Conservation Area; OMUs: One-male units

\section{Acknowledgements}

The following are duly acknowledged: The Ethiopian Ministry of Education for providing the research grant, Staff of Guassa Community Conservation Management and the local administration for providing all the necessary support during data collection, and the anonymous reviewers for their critical assessment and valuable comments.

\section{Authors' contributions}

MM collected the field data and prepared the draft manuscript. TW developed the research idea and designed the methods, analyzed the data, and finalized the manuscript in its current form. All authors read and approved the final manuscript.

Funding

The study was funded by the Ethiopian Ministry of Education.

\section{Availability of data and materials}

The datasets used and/or analyzed during the current study are available from the corresponding author on reasonable request.

\section{Competing interest}

The authors declare that they have no competing interests.

Ethics approval and consent to participate

Not applicable

\section{Consent for publication}

Not applicable

Received: 15 January 2019 Accepted: 13 June 2019

Published online: 26 June 2019

\section{References}

Abie K, Bekele A, Mekonen A. Daily activity, feeding ecology and habitat association of gelada baboon (Theropithecus gelada) around Debre-Libanos, Northwest Shewa Zone, Ethiopia. Internat J Biodivers Conserv. 2017;9(6):232-

Altmann J. Observational study of behavior: sampling method. Behavior. 1974:49: 227-67.

Andarge E. Human wildlife conflict involving Ethiopian Wolf (Canis simensis) and Gelada baboons (Theropithecus gelada) in and around Guassa Community Conservation Area. Addis Ababa: M.Sc. Thesis, Addis Ababa University; 2010.

Bronson FH. Energy balance and ovulation: small cages versus natural habitats. Reprod Fertil Dev. 1998;10(2):127-38.

Dunbar RIM. Determinants and evolutionary consequences of dominance among female gelada baboons. Behav EcolSociobiol. 1980;7(4):253-65.

Dunbar RIM. Structure of gelada baboon reproductive units. Ethol Internat J Behavior Ecol. 1983;63(4):265-82. 
Dunbar RIM. Functional significance of social grooming in primates. Folia Primatol. 1991:57:121-31.

Dunbar RIM, Dunbar P. Dominance and reproductive success among female gelada baboons. Nature. 1977;266:351-2.

Dunbar RIM, Dunbar P. Maternal time budgets of gelada baboons. Anim Behav. 1988;36(4):970-80.

Filipcik R, Machal L, Baholet D, Chladek G, Hosek M, Paldusova M. The daily pattern of main activities in the gelada baboon (Theropithecus gelada). Acta. 2014;62:891-6.

Gippoliti S, Hunter C. Theropithecus gelada. The IUCN Red List of threatened Species 2008: https://doi.org/10.2305/IUCN.UK.2008.RLTS.T21744A9316114.en. Accessed 28 Apr 2018.

Gron KJ. Primate Factsheets: Gelada baboon (Theropithecus gelada) taxonomy, morphology, \& ecology. 2008. http://pin.primate.wisc.edu/factsheets/entry/ gelada_baboon. Accessed 16 May 2018.

Iwamoto T, Dunbar R. Thermoregulation, habitat quality and the behavioral ecology of gelada baboons. J Anim Ecol. 1983;52:357-66.

Kawai M, Dunbar RIM, Ohsawa H, Mori U. Social organization of gelada baboons: social units and definitions. Primates. 1983;24(1):13-24

Lehmann J, Korstjens AH, Dunbar RIM. Group size and social cohesion in primates. Anim Bhav. 2007;74(6):1617-29.

Mancini G, Palagi E. Play and social dynamics in a captive herd of gelada baboons (Theropithecus gelada). Behav Processes. 2009:82(3):286-92.

Palagi E, Leone A, Mancini G, Ferrari P. Contagious yawning in gelada baboons as a possible expression of empathy. Proc Nati Acad Sci USA. 2009;106(46): 19262-7.

Roux AL, Beehner JC, Bergman TJ. Female philopatry and dominance patterns in wild geladas. Am J Primatol. 2011;73:422-30.

Snyder-Mackler N, Beehner JC, Bergman TJ. Defining higher levels in the multilevel societies of Gelada (Theropithecus gelada). Int J Primatol. 2012; 33(5):1054-68.

Tefera Z. Common property resource management of Afro-alpine habitat supporting a population of a critically endangered Ethiopian Wolf (Cannis simensis), PhD. Thesis, Durrel, Institute of Conservation and Ecology, University of Kent, Canterbury; 2001.

Tefera Z. Community management of Afro alpine highlands Ethiopia. LEISA Magazine. Addis Ababa; 2005

Tefera Z, Leader-Williams N. Behaviour and ecology of the Ethiopian wolf (Canis simensis) in human-dominated landscape outside protected areas. Anim Conserv. 2005:8:113-21.

Vaughan TA, Ryan JM, Czaplewski NJ. Mammalogy. 4th ed. United States of America: Thomson Learning Inc; 2000.

Walker EP. Mammals of the World. 3rd ed. Volume I. Baltimore and London: The Johns Hopkins University Press; 1975.

Woldegeorgis C, Bekele A. Activity budget and behavioral patterns of gelada (Mammalia: Primates: Cercopithecidae) on the Gich Plateau of the Simien Mountains National Park, Ethiopia. JoTT. 2015;7(8):7409-15.

Yalden DW, Largen MJ, Kock D. Catalogue of the mammals of Ethiopia. Monitore Zoologico Italiano (NS) Suppl. 1977;9:1-52.

\section{Publisher's Note}

Springer Nature remains neutral with regard to jurisdictional claims in published maps and institutional affiliations.

Ready to submit your research? Choose BMC and benefit from:

- fast, convenient online submission

- thorough peer review by experienced researchers in your field

- rapid publication on acceptance

- support for research data, including large and complex data types

- gold Open Access which fosters wider collaboration and increased citations

- maximum visibility for your research: over $100 \mathrm{M}$ website views per year

At $\mathrm{BMC}$, research is always in progress.

Learn more biomedcentral.com/submissions 